\title{
The Influence of Design and Operational Factors on the Removal of Personal Care Products by Constructed Wetlands
}

\author{
Huma Ilyas ${ }^{1,2, * \mathbb{D}}$ and Eric D. van Hullebusch ${ }^{1}$ (D) \\ 1 Institut de physique du globe de Paris, Université de Paris, CNRS, F-75005 Paris, France; \\ vanhullebusch@ipgp.fr \\ 2 Water Treatment and Management Consultancy, B.V., 2289 ED Rijswijk, The Netherlands \\ * Correspondence: hi.wtmconsult@gmail.com
}

Received: 12 April 2020; Accepted: 8 May 2020; Published: 12 May 2020

\begin{abstract}
This research presents the correlation analysis of selected design and operational factors (depth, area, hydraulic and organic loading rate, and hydraulic retention time), and physicochemical parameters ( $\mathrm{pH}$, temperature, and dissolved oxygen) of constructed wetlands (CWs) with the removal efficiency of personal care products (PCPs). The results demonstrated that the removal efficiencies of the studied PCPs exhibit a significant correlation with two or more of these factors. The role of plants in the removal of PCPs is demonstrated by the higher performance of planted compared with unplanted CWs due to direct uptake of PCPs and their aerobic biodegradation. The enhanced removal of PCPs was achieved with the use of substrate material of high adsorption capacity and with high surface area in CWs. The removal efficiency of almost all of the studied PCPs revealed seasonal differences, but significant difference was established in the case of galaxolide and methyl dihydrojasmonate. Most of the examined PCPs demonstrated adsorption and/or sorption as their most dominant removal mechanism followed by biodegradation and plant uptake. Therefore, the efficient removal of PCPs demands the integrated design ensuring suitable environment for the occurrence of these processes along with the optimal values of design and operational factors, and physicochemical parameters.
\end{abstract}

Keywords: constructed wetlands; design and operational parameters; personal care products; physicochemical parameters; removal efficiency; removal mechanisms; wastewater

\section{Introduction}

Constructed wetlands (CWs) were comprehensively investigated for the treatment of personal care products (PCPs) from wastewater. Among the investigated CWs are free water surface CW (FWSCW), horizontal flow CW (HFCW), vertical flow CW (VFCW), and hybrid CW (HCW) (Tables S1-S4, Supplementary Materials). As summarized in Table 1, most of the studies considered one or more topics for evaluation, such as role of design and/or operational factors, role of physicochemical parameters, effect of plants and/or support matrix, and impact of seasonality (summer and winter) on the removal of PCPs in CWs. Several individual studies emphasized the role of plants in the removal of PCPs by investigating the performance of planted and unplanted CWs (Table 1). Some recent studies investigated the effect of support matrix on the removal of PCPs by using the substrate material of high adsorption capacity and with high surface area (Table 1). The influence of other governing factors on the performance of CWs for the removal of PCPs such as the physicochemical parameter $(\mathrm{pH}$, temperature, and dissolved oxygen-DO) and operational factors (hydraulic loading rate-HLR and hydraulic retention time-HRT) was examined by some researchers (Table 1). Furthermore, several studies considered the effect of seasonality (summer and winter) on the removal of PCPs to emphasize 
the impact of temperature on their removal mechanisms in CWs (Table 1). An in-depth examination of these studies revealed that correlation analysis of design and operational factors, and physicochemical parameters with the removal efficiency of PCPs was conducted within individual studies (also a limited number) but not between studies, as well as for the removal of a limited number of PCPs. For instance, in the case of operational factors, the correlation analysis was conducted only on the role of HRT in the removal of PCPs and by Matamoros and Salvadó [1]. Similarly, in the case of physicochemical parameters, the correlation analysis to investigate their impact on the removal of PCPs was conducted by Hijosa-Valsero et al. [2,3] and Vymazal et al. [4].

Table 1. The design, operational, and physicochemical parameters of studied constructed wetlands (CWs) and corresponding references.

\begin{tabular}{|c|c|}
\hline $\begin{array}{l}\text { Design, Operational, and } \\
\text { Physicochemical Parameters }\end{array}$ & References \\
\hline \multicolumn{2}{|l|}{ Operational Factors } \\
\hline Hydraulic loading rate & Matamoros et al. [5]; Ávila et al. [6,7]; Dai et al. [8] \\
\hline Organic loading rate & Matamoros et al. [9] \\
\hline Hydraulic retention time & $\begin{array}{l}\text { Matamoros et al. [10]; Matamoros and Salvadó [1]; Ávila et al. [6]; } \\
\text { Herrera-Cárdenas et al. [11]; Vymazal et al. [4]; Vystavna et al. [12]; } \\
\text { Salcedo et al. [13] }\end{array}$ \\
\hline \multicolumn{2}{|l|}{ Physicochemical Parameters } \\
\hline $\mathrm{pH}$ & Hijosa-Valsero et al. $[2,3]$ \\
\hline Temperature & $\begin{array}{l}\text { Hijosa-Valsero et al. [2,3]; Ávila et al. [14]; Matamoros et al. [9,15]; } \\
\text { Vymazal et al. [4] }\end{array}$ \\
\hline Dissolved oxygen & $\begin{array}{l}\text { Hijosa-Valsero et al. [2]; Ávila et al. [6,7,14]; Chen et al. [16]; Kahl et al. [17]; } \\
\text { Li et al. [18]; Vymazal et al. [4]; Nivala et al. [19] }\end{array}$ \\
\hline Planted and Unplanted CWs & $\begin{array}{l}\text { Hijosa-Valsero et al. [2,3,20]; Reyes-Contreras et al. [21]; } \\
\text { Carranza-Diaz et al. [22]; Salcedo et al. [13]; Button et al. [23] }\end{array}$ \\
\hline Role of Support Matrix & Ávila et al. [6]; Salcedo et al. [13]; Xie et al. [24]; Nivala et al. [19] \\
\hline $\begin{array}{l}\text { Effect of Seasonality } \\
\text { (summer and winter) }\end{array}$ & $\begin{array}{l}\text { Matamoros et al. [10,15]; Hijosa-Valsero et al. [2,3]; Reyes- } \\
\text { Contreras et al. [21] }\end{array}$ \\
\hline
\end{tabular}

Furthermore, only a few studies reviewed and summarized the available knowledge on some of the abovementioned topics with specific focus on PCPs removal by CWs [25-28]. Although these review studies contributed in advancing the scientific knowledge on the removal of PCPs by CWs, these studies were constrained by a limited number of existing studies on certain topics and also considered a limited number of PCPs. Moreover, a lack of detailed statistical analysis (e.g., meta-analysis) to establish significant correlation between PCPs removal and governing factors (design and operational factors, and physicochemical parameters) require conducting further research to infer evidence based general conclusions.

Therefore, the main objectives of this study are (1) to critically evaluate and summarize the available evidence on major PCPs removal mechanisms in CWs, (2) to explore the role of design and operational factors of CWs in PCPs removal, (3) to examine the impact of physicochemical parameters of CWs on PCPs removal, (4) to evaluate the role of plants and a support matrix of CWs in PCPs removal, and (5) to investigate the effect of seasonality on the performance of CWs for PCPs removal.

\section{Methods}

This research is based on the secondary data and a critical review of the published literature. The research papers, review papers, and books were searched in various sources, such as Scopus, Google Scholar, and individual journal websites, related to the performance of different types of CWs for the removal of different categories of PCPs. The snowball sampling method yielded over 50 journal articles published up to 2019, which were further screened and used for the purpose of this research. 
Screening was carried out to check the quality of the published data. Only peer-reviewed journal papers were selected for this research, which helped to ensure the reliability of given data. The selected studies have used generally accepted and reliable analytical methods such as solid phase extraction-gas chromatography-tandem mass spectrometry (SPE-GC-MS/MS), SPE-(ultra) high performance liquid chromatography-MS/MS (SPE-(U)HPLC-MS/MS), and liquid-liquid phase extraction-(U)HPLC-MS/MS (LLPE-(U)HPLC-MS/MS). Instrumental detection and quantification limits described as limit of detection and limit of quantification were in the range of $0.0002-1.0 \mu \mathrm{g} \mathrm{L}^{-1}$ and $0.00005-0.8 \mu \mathrm{g} \mathrm{L}^{-1}$, respectively. The samples were analyzed soon after collection, as the storage time was less than one or two days in most cases. The selected studies contained the required information on most of the key parameters such as concentration of PCPs in influent and effluent waters, removal efficiency, biochemical oxygen demand (BOD), chemical oxygen demand (COD), HLR, and HRT. In this way, a global database was compiled containing information on $137 \mathrm{CWs}$ that were reported in 39 peer reviewed journal publications with case studies from 13 countries (Tables S1-S4, Supplementary Materials). This database contains influent and effluent concentrations, removal efficiencies, and removal rates of 20 PCPs grouped in seven categories according to their uses (Table 2).

Table 2. Studied 20 personal care products (PCPs) categorized according to their uses.

\begin{tabular}{ccl}
\hline $\begin{array}{c}\text { No. of } \\
\text { Categories }\end{array}$ & Category & \multicolumn{1}{c}{ Personal Care Products } \\
\hline 1 & Artificial sweetener & Sucralose, Acesulfame \\
2 & Preservatives & Methylparaben, Propylparaben \\
N, N-diethyl-3-methyl benzoylamide, N, N-diethyl-3-methylbenzamide, \\
N, N-diethyl-meta-toluamide \\
4 & Insect repellent & Triclosan, Triclocarban \\
5 & Antiseptics & Cashmeran, Celestolide, Galaxolide, Methyl dihydrojasmonate, Tonalide \\
6 & Fragrances & Tributyl phosphate, Triphenyl phosphate, \\
7 & Flame retardants & Tris (2-chloroethyl) phosphate \\
\hline
\end{tabular}

The design, operational, and physicochemical parameters of CWs such as treatment scale and type, wastewater type, depth, area, HLR, organic loading rate (OLR), HRT, experiment duration, system age, filter media, temperature, $\mathrm{pH}$, effluent $\mathrm{DO}$, and oxidation-reduction potential (ORP) of four types of CWs (FWSCW, HFCW, VFCW, and HCW) were considered to examine their influence on the removal of PCPs. Some of these parameters are summarized in Table 3; details are provided in Tables S1-S4 (Supplementary Materials). The information on the physicochemical properties of PCPs was gathered from various sources (e.g., journal papers, reports, and websites) for molecular formula/structure/weight, water solubility, dissociation constant (pKa), organic carbon sorption coefficient (Log Koc), octanol-water partition coefficient (Log Kow), and distribution coefficient (Log Dow) (Table S5, Supplementary Materials).

Firstly, a comprehensive analysis of the investigated PCPs was carried out based on the studied literature and the mechanisms responsible for their removal were identified (Table 4). Secondly, statistical analysis was conducted to estimate the mean and standard deviation of the selected studied variables. Pearson correlation was estimated to examine the influence of selected design and operational factors (depth, area, HLR, HRT, and OLR), and physicochemical parameters $(\mathrm{pH}$, temperature, and effluent $\mathrm{DO})$ on the performance of CWs for PCPs removal. The statistical comparison between planted and unplanted CWs, as well as in summer and winter seasons for the removal efficiency of PCPs was done with a z-Test for comparison of means. 
Table 3. Summary of selected design, operational, and physicochemical parameters of the studied four types of CWs.

\begin{tabular}{|c|c|c|c|c|}
\hline $\begin{array}{l}\text { Design, Operational, } \\
\text { and Physicochemical Parameters }\end{array}$ & FWSCW & HFCW & VFCW & HCW \\
\hline Number of CWs & 24 & 57 & 12 & 38 \\
\hline Number of studies & 8.0 & 15 & 8.0 & 19 \\
\hline Scale of application & Lab, Pilot, Full & Lab, Pilot, Full & Lab, Pilot & Lab, Pilot, Full \\
\hline Type of treatment & $\begin{array}{c}\text { Primary, } \\
\text { Secondary, Tertiary }\end{array}$ & $\begin{array}{c}\text { Primary, } \\
\text { Secondary, Tertiary }\end{array}$ & $\begin{array}{l}\text { Primary, } \\
\text { Secondary }\end{array}$ & $\begin{array}{c}\text { Primary, } \\
\text { Secondary, Tertiary }\end{array}$ \\
\hline Depth (m) & $0.8 \pm 0.9$ & $0.5 \pm 0.1$ & $0.8 \pm 0.1$ & $0.8 \pm 0.4$ \\
\hline Area $\left(\mathrm{m}^{2} \mathrm{PE}^{-1}\right)$ & $12 \pm 8$ & $6.6 \pm 5.7$ & $4.3 \pm 3.4$ & $9.0 \pm 6.9$ \\
\hline $\operatorname{HLR}\left(\mathrm{m}^{3} \mathrm{~m}^{-2} \mathrm{~d}^{-1}\right)$ & $0.1 \pm 0.1$ & $0.5 \pm 1.1$ & $0.07 \pm 0.03$ & $0.1 \pm 0.3$ \\
\hline $\operatorname{OLR}\left(\mathrm{g} \mathrm{COD} \mathrm{m}^{-2} \mathrm{~d}^{-1}\right)$ & $15 \pm 18$ & $32 \pm 20$ & $27 \pm 20$ & $24 \pm 30$ \\
\hline HRT (days) & $6.1 \pm 9.4$ & $4.9 \pm 4.6$ & $3.2 \pm 3.2$ & $4.7 \pm 7.8$ \\
\hline $\mathrm{pH}$ & $6.9 \pm 0.3$ & $7.4 \pm 0.6$ & $7.4 \pm 0.7$ & $7.4 \pm 0.4$ \\
\hline Temperature $\left({ }^{\circ} \mathrm{C}\right)$ & $13 \pm 6$ & $17 \pm 6$ & $19 \pm 2$ & $15 \pm 6$ \\
\hline Effluent DO (mg L $\left.{ }^{-1}\right)$ & $1.4 \pm 2.4$ & $1.7 \pm 2.2$ & $5.4 \pm 3.0$ & $2.0 \pm 1.9$ \\
\hline
\end{tabular}

Note: Free water surface CW (FWSCW); horizontal flow CW (HFCW); vertical flow CW (VFCW); hybrid CW $(\mathrm{HCW})$; population equivalent (PE); hydraulic loading rate (HLR); organic loading rate (OLR); chemical oxygen demand (COD); hydraulic retention time (HRT); dissolved oxygen (DO).

\section{Results and Discussion}

\subsection{Removal Mechanisms of PCPs in CWs}

In CWs various physical, chemical, and biological processes such as volatilization, photodegradation, adsorption/sorption, biodegradation, and plant uptake occur at the same time (Figure 1). However, the dominance of removal mechanisms depends on the design of CWs [26,29]. For instance, in FWSCW, the major removal mechanism of PCPs is photodegradation, though biodegradation and plant uptake also contribute to the overall performance. In HFCW and VFCW, due to the prevailing anaerobic and aerobic conditions, the corresponding anaerobic and aerobic biodegradation is obvious for the removal of PCPs among other main processes such as sedimentation and adsorption.

The removal mechanisms are identified for 15 out of 20 examined PCPs for which three or more data points were available. In most of the examined PCPs, adsorption to the substrate and/or sorption to organic surfaces is the most dominant removal mechanism followed by biodegradation (aerobic and anaerobic), and plant uptake (planted CWs), which explains the variation in their removal efficiency in different types of CWs (FWSCW, HFCW, VFCW, and HCW) (Table S6, Supplementary Materials). Several researchers suggest that physicochemical properties of PCPs play a crucial role in their removal mechanisms in CWs (Table 4, Table S5, Supplementary Materials). The physicochemical properties of PCPs, which play considerable role in the removal processes, are governed by molecular weight/structure, solubility in water, Log Koc, Log Kow, Log Dow, cationic or anionic nature (pKa/charge), and presence of certain elements (e.g., chlorine) (Table S5, Supplementary Materials). Detailed discussion on the performance comparison of different types of CWs and on the role of physicochemical properties of PCPs in their removal mechanisms can be found in Ilyas and van Hullebusch [30]. 


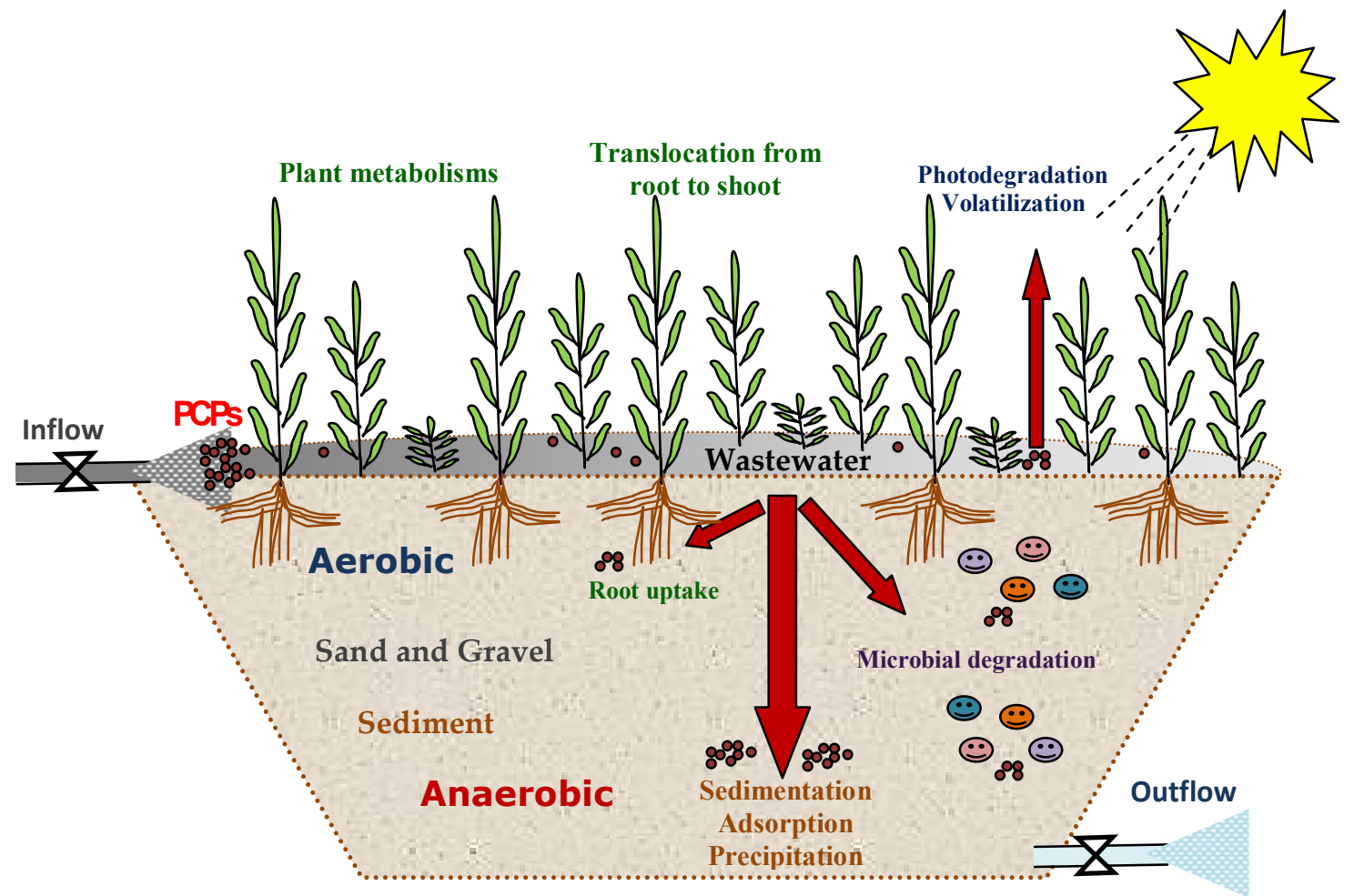

Figure 1. A schematic representation of the removal mechanisms of personal care products (PCPs) in constructed wetlands (CWs).

Table 4. Removal mechanisms of 15 widely studied PCPs in CWs.

\begin{tabular}{|c|c|c|c|}
\hline Class/PCPs & $\begin{array}{l}\text { Possible Removal } \\
\text { Mechanism }\end{array}$ & References & $\begin{array}{l}\text { Dominant Removal } \\
\text { Mechanism * }\end{array}$ \\
\hline \multicolumn{4}{|l|}{ Artificial sweeteners } \\
\hline Acesulfame & Biodegradation (aerobic) & Kahl et al. [17]; Nivala et al. [19] & $\begin{array}{l}\text { Biodegradation } \\
\text { (aerobic) }\end{array}$ \\
\hline \multicolumn{4}{|l|}{ Preservatives } \\
\hline \multirow[t]{2}{*}{ Methylparaben } & Plant uptake & Anjos et al. [31]; Petrie et al. [32] & $\begin{array}{c}\text { Plant uptake; } \\
\text { Biodegradation } \\
\text { (aerobic); } \\
\text { Photodegradation ** }\end{array}$ \\
\hline & $\begin{array}{l}\text { Biodegradation } \\
\text { (aerobic) } \\
\text { Photodegradation } \\
\text { Hydrolysis } \\
\text { Volatilization }\end{array}$ & $\begin{array}{l}\text { Matamoros et al. [9,15]; } \\
\text { Anjos et al. [31]; Chen et al. [33] } \\
\text { Chen et al. [33] } \\
\text { Chen et al. [33] } \\
\text { Chen et al. [33] }\end{array}$ & \\
\hline \multirow[t]{3}{*}{ Propylparaben } & Plant uptake & Anjos et al. [31] & $\begin{array}{c}\text { Plant uptake; } \\
\text { Biodegradation } \\
\text { (aerobic); } \\
\text { Photodegradation ** }\end{array}$ \\
\hline & $\begin{array}{l}\text { Biodegradation } \\
\text { (aerobic) }\end{array}$ & Anjos et al. [31] & \\
\hline & Photodegradation & NA & \\
\hline \multicolumn{4}{|l|}{ Insect repellents } \\
\hline \multirow[t]{2}{*}{$\mathrm{N}$, N-diethyl-meta-toluamide } & Biodegradation (aerobic) & Li et al. [18]; Sgroi et al. [34] & $\begin{array}{l}\text { Biodegradation } \\
\text { (anaerobic) }{ }^{* *}\end{array}$ \\
\hline & $\begin{array}{l}\text { Biodegradation } \\
\text { (anaerobic) }\end{array}$ & Yi et al. [35]; Sgroi et al. [34] & \\
\hline
\end{tabular}


Table 4. Cont.

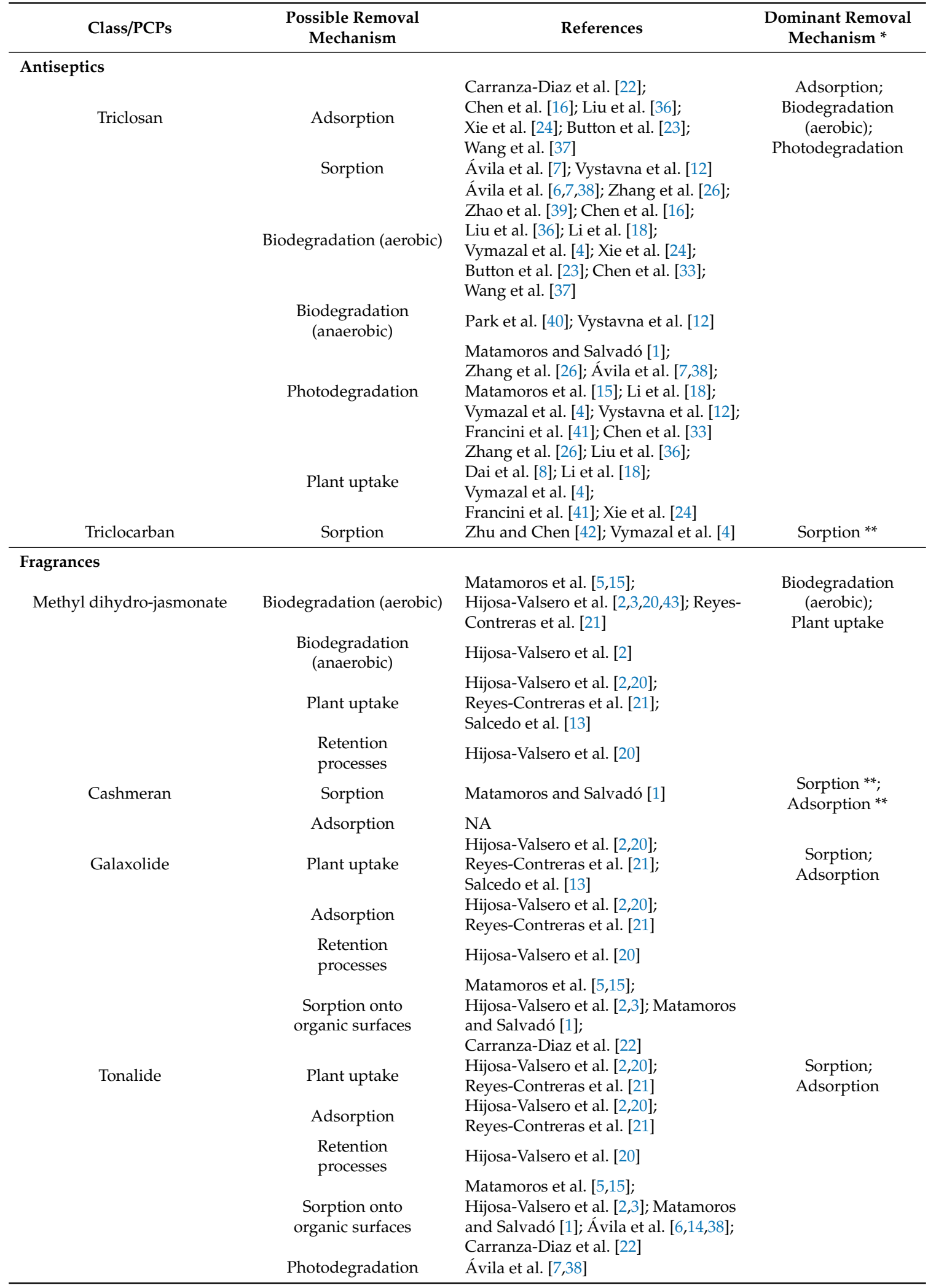


Table 4. Cont

\begin{tabular}{|c|c|c|c|}
\hline Class/PCPs & $\begin{array}{l}\text { Possible Removal } \\
\text { Mechanism }\end{array}$ & References & $\begin{array}{c}\text { Dominant Removal } \\
\text { Mechanism * }\end{array}$ \\
\hline \multicolumn{4}{|l|}{ Flame retardants } \\
\hline \multirow[t]{2}{*}{ Tributyl phosphate } & Biodegradation & Matamoros et al. [15] & $\begin{array}{l}\text { Sorption **; } \\
\text { Biodegradation } \\
\quad\left(\text { aerobic) }{ }^{* *}\right.\end{array}$ \\
\hline & Sorption & NA & \multirow[b]{2}{*}{$\begin{array}{c}\text { Biodegradation } \\
\text { (aerobic) }{ }^{* *} ; \\
\text { Sorption }^{* *}\end{array}$} \\
\hline Triphenyl phosphate & Biodegradation & Matamoros et al. [15] & \\
\hline \multirow{4}{*}{ Tris (2-chloroethyl) phosphate } & Sorption & NA & \multirow{4}{*}{ Sorption ** } \\
\hline & $\begin{array}{l}\text { Recalcitrant to } \\
\text { biodegradation }\end{array}$ & $\begin{array}{l}\text { Matamoros and Salvadó [1]; } \\
\text { Matamoros et al. }[9,15]\end{array}$ & \\
\hline & Sorption & NA & \\
\hline & Plant uptake & NA & \\
\hline \multicolumn{4}{|l|}{ Sunscreen agents } \\
\hline \multirow[t]{3}{*}{ Oxybenzone } & Biodegradation (aerobic) & $\begin{array}{l}\text { Matamoros and Salvadó [1]; } \\
\text { Ávila et al. }[6,7,14]\end{array}$ & \multirow[t]{3}{*}{$\begin{array}{c}\text { Adsorption }{ }^{* *} ; \\
\text { Biodegradation } \\
\text { (aerobic); Sorption }\end{array}$} \\
\hline & Sorption & Matamoros and Salvadó [1] & \\
\hline & Adsorption & NA & \\
\hline Sulisobenzone & NA & NA & $\begin{array}{l}\text { Biodegradation } \\
\text { (aerobic) }\end{array}$ \\
\hline
\end{tabular}

Note: Authors' own insight based on physicochemical properties, removal mechanisms, and limited evidence in the literature $\left({ }^{*}\right)$. Authors' own insight based on physicochemical properties and removal mechanisms $\left({ }^{* *}\right)$.

\subsection{Influence of Design and Operational Factors of CWs on the Removal of PCPs}

The Pearson correlation statistics presented in Table S7 (Supplementary Materials) revealed that design and operational parameters of CWs such as depth, area, OLR, HLR, and HRT play an essential role in their performance for the removal of PCPs, though the level of their influence is variable. Furthermore, it is noteworthy that the removal of PCPs in CWs might not only relate to one design and/or operational parameter; all the parameters might directly or indirectly impact their removal.

\subsubsection{Depth}

The depth revealed a positive correlation with the removal efficiency of five out of six studied PCPs, although exhibited a significant positive correlation only with the removal efficiency of tonalide and oxybenzone (Figure 2; Table S7, Supplementary Materials). Rühmland et al. [44] demonstrated that biodegradation is the major removal pathway of emerging organic contaminants (EOCs) during in situ degradation experiment by achieving their almost similar removal at all water depths, as well as in the dark control. The adsorption to the substrate media and sorption onto carbon rich surfaces are slow processes [32], which might contribute more efficiently when the depth of the system is increased, which indirectly increases contact time with the media. Therefore, the positive correlation of the removal efficiency of PCPs with depth indicates the major contribution of biodegradation (aerobic and anaerobic) in the removal of triclosan, methylparaben, and oxybenzone (Table 4). The positive correlation with the removal efficiency of tonalide and galaxolide suggests their adsorption and sorption onto organic surfaces (Table 4). On the other hand, the removal efficiency of methyl dihydrojasmonate demonstrates a negative correlation with the depth of the system (although non-significant), which designates that uptake by the plants is its major removal mechanism, which is more appropriate when the system is not very deep so that the roots of the plants can easily take up the PCPs. 


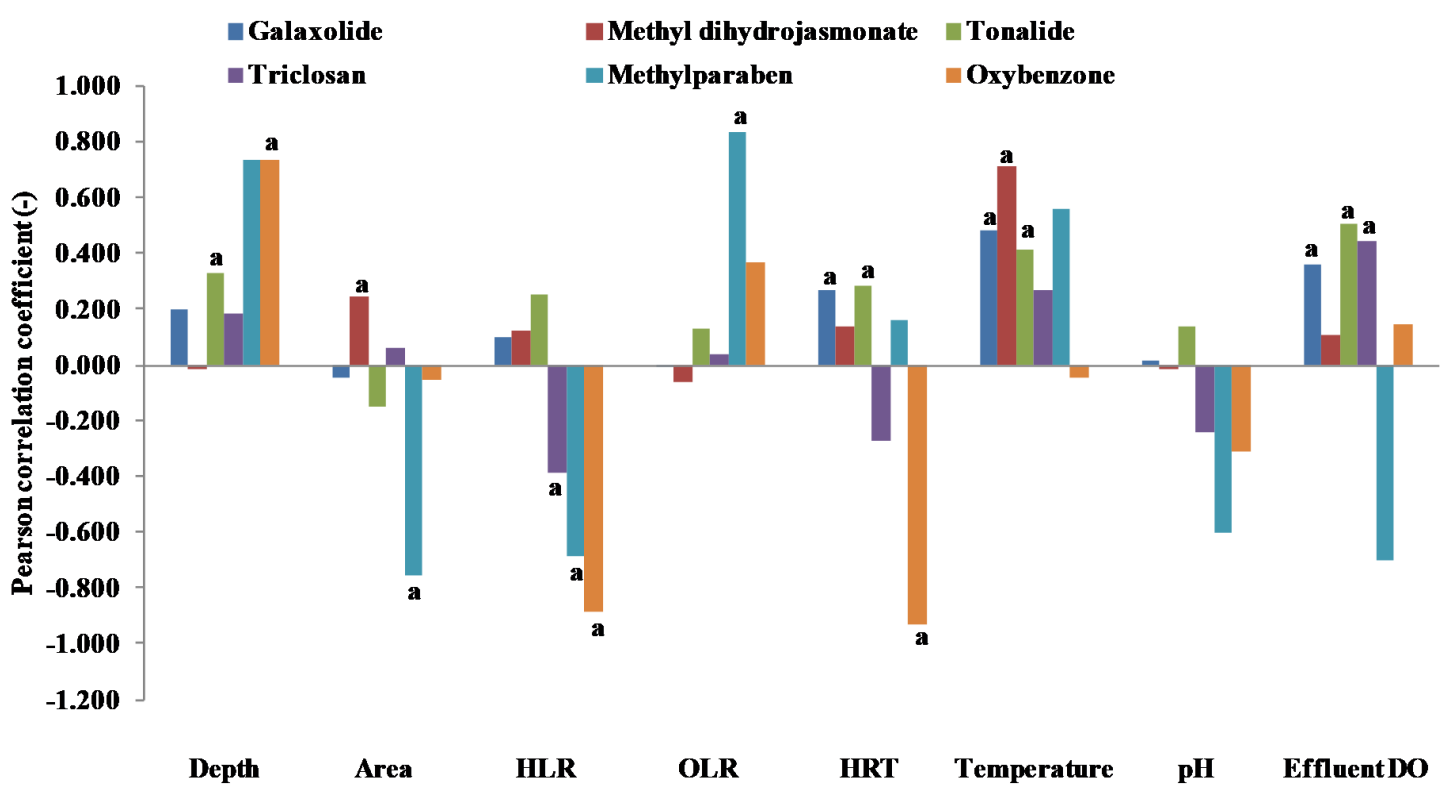

Figure 2. Pearson correlation statistics among the studied factors and the removal efficiency of six selected PCPs. Note: "a" shows a significant correlation between the parameters at $95 \%$ confidence level. The number of studies reporting these parameters are different and hence the number of data points. Galaxolide: the number of data points in the case of depth, area, HLR, OLR, HRT, temperature, $\mathrm{pH}$, and effluent DO were 73, 73, 73, 72, 70, 45, 39, and 48, respectively; Methyl dihydrojasmonate: the number of data points in the case of depth, area, HLR, OLR, HRT, temperature, $\mathrm{pH}$, and effluent DO were $75,76,76,75,73,49,37$, and 52, respectively; Tonalide: the number of data points in the case of depth, area, HLR, OLR, HRT, temperature, $\mathrm{pH}$, and effluent DO were 53, 55, 57, 54, 52, 53, 47, and 54, respectively; Triclosan: the number of data points in the case of depth, area, HLR, OLR, HRT, temperature, $\mathrm{pH}$, and effluent DO were 31, 32, 39, 33, 35, 20, 21, and 24, respectively; Methylparaben: the number of data points in the case of depth, area, HLR, OLR, HRT, temperature, pH, and effluent DO were $6,7,10,7,8,7,4$, and 7, respectively; Oxybenzone: the number of data points in the case of depth, area, HLR, OLR, HRT, temperature, pH, and effluent DO were 10, 11, 14, 10, 10, 13, 9, and 12 , respectively.

\subsubsection{Area}

Area exhibited a significant positive correlation with the removal efficiency of methyl dihydrojasmonate (Figure 2; Table S7, Supplementary Materials). Although the cost of operation increases due to large land area, the resulting longer HRT contributes to the performance enhancement of CWs for PCPs removal $[1,10,11]$, which are removed by slow processes such as adsorption to the substrate media, sorption onto the organic surfaces, plant uptake, anaerobic biodegradation, and photodegradation [10,32,45]. Herrera-Cárdenas et al. [11] achieved the enhanced removal of methyl dihydrojasmonate with increase in HRT from three to five days ( $50 \%$ and $70 \%$, respectively) in an HFCW, and the removal of methyl dihydrojasmonate is attributed to plant uptake by several researchers (Table 4). The removal of triclosan is ascribed to adsorption and/or sorption, photodegradation, plant uptake, as well as anaerobic biodegradation (Table 4). In contrast, the significant negative correlation of the removal efficiency of methylparaben with land area, which is mainly removed by plant uptake, as well as the negative correlation (although non-significant) of the removal efficiency of tonalide and galaxolide, which are removed by their adsorption and sorption onto organic surfaces (Table 4), suggests a more significant impact of other design and operational parameters on their removal.

\subsubsection{HLR}

The significant negative correlation of HLR with the removal efficiency of three PCPs (triclosan, methylparaben, and oxybenzone) (Figure 2; Table S7, Supplementary Materials) indicates the reduction 
in their removal with increasing HLR [5-8] in HFCW, VFCW, and HCW. This is evident by the reduction in removal efficiency of tonalide, oxybenzone, and triclosan at an HLR of $0.13 \mathrm{~m}^{3} \mathrm{~m}^{-2} \mathrm{~d}^{-1}(85 \%, 92 \%$, and $92 \%$, respectively) compared with an HLR of $0.06 \mathrm{~m}^{3} \mathrm{~m}^{-2} \mathrm{~d}^{-1}(95 \%, 96 \%$, and $96 \%$, respectively) in HCWs [7] (Table S4, Supplementary Materials). A higher HLR translates to a high number of pulses per day, which reduces the oxygen transfer capacity. Similarly, the removal of hydrophobic compounds attributed to their adsorption onto particulate matter decreases due to lower contact time [7]. Therefore, if the system is operated at high HLR for a longer period of time, the removal efficiency of PCPs, which are removed by aerobic biodegradation and adsorption onto particles is significantly affected [8]. Several studies attributed the removal of triclosan and oxybenzone to aerobic biodegradation, as well as adsorption of triclosan to the substrate (Table 4). On the other hand, the positive correlation (although non-significant) of the removal efficiency of methyl dihydrojasmonate, tonalide, and galaxolide, which are removed by plant uptake, and their adsorption and sorption onto organic surfaces (Table 4) designates that other design and operational parameters might play more crucial role in their removal in CWs.

\subsubsection{OLR}

OLR demonstrated a positive correlation with the removal efficiency of tonalide, triclosan, methylparaben, and oxybenzone, although a significant positive correlation only with the removal efficiency of methylparaben (Figure 2; Table S7, Supplementary Materials). The enhanced removal efficiency of tonalide, triclosan, oxybenzone, and methylparaben was observed in HFCW upon increasing OLR from $14 \mathrm{~g} \mathrm{COD} \mathrm{m}^{-2} \mathrm{~d}^{-1}\left(41 \%, 67 \%, 74 \%\right.$, and $16 \%$, respectively) to $38 \mathrm{~g} \mathrm{COD} \mathrm{m}^{-2}$ $\mathrm{d}^{-1}(51 \%, 73 \%, 85 \%$, and 60\%, respectively) [9] (Table S2, Supplementary Materials). The negative correlation of OLR with the removal efficiency of galaxolide and methyl dihydrojasmonate (Figure 2) designates the negative influence of wastewater strength, indicating the higher performance of the system loaded with low strength wastewater and vice versa. In contrast, Matamoros et al. [9] reported the improvement in the removal efficiency of galaxolide and methyl dihydrojasmonate in HFCW upon increasing OLR from $14 \mathrm{~g} \mathrm{COD} \mathrm{m}^{-2} \mathrm{~d}^{-1}$ (42\% and 56\%, respectively) to $38 \mathrm{~g} \mathrm{COD} \mathrm{m}^{-2} \mathrm{~d}^{-1}$ (59\% and 60\%, respectively) (Table S2, Supplementary Materials). The HLR of the system exhibits a positive correlation with OLR. The microbial activity for the degradation of pollutants enhances when the organic matter is added into the wetlands but to a certain HLR. However, if the HLR increases beyond the loading capacity of the system, the reduction in HRT decreases the contact time of pollutants with the microbes, which leads to the poor treatment performance of the system. In addition to that, the porosity of the CWs could be reduced due to microbial overproduction and plant growth at high HLR [46]. Several studies ascribed the removal to adsorption and/or sorption in the case of galaxolide and aerobic biodegradation to methyl dihydrojasmonate (Table 4). On the other hand, the positive correlation of the removal efficiency of triclosan and methylparaben with OLR indicates that their removal is favored by several other pathways including biodegradation (anaerobic), hydrolysis, volatilization, and photodegradation (Table 4).

\subsubsection{HRT}

HRT revealed a significant correlation with the removal efficiency of three PCPs (galaxolide, tonalide, and oxybenzone) (Figure 2; Table S7, Supplementary Materials). The different mechanisms contribute to the removal of PCPs in CWs including adsorption, sorption, plant uptake, anaerobic biodegradation, and photodegradation are slow processes [10,12,32,45], which necessitate the availability of longer HRT in CWs for their improved removal. Several studies attributed the removal of galaxolide and tonalide to adsorption and sorption onto organic surfaces, which is evident by the significant positive correlation of their removal efficiency with HRT (Figure 2; Table 4, Table S7, Supplementary Materials). Similarly, the removal efficiency of methyl dihydrojasmonate and methylparaben showed a positive correlation with HRT (although non-significant) (Figure 2; Table S7, Supplementary Materials), which are mainly removed by plant uptake (Table 4). Salcedo et al. [13] 
reported the enhanced removal of galaxolide and methyl dihydrojasmonate in HFCW with increasing HRT from one to five days. The corresponding removal efficiency of galaxolide was $50 \pm 14 \%$ and $88 \pm$ $4 \%$, respectively, and the removal efficiency of methyl dihydrojasmonate was $59 \pm 16 \%$ and $91 \pm 5 \%$, respectively. The removal efficiency of oxybenzone exhibits a significant negative correlation with HRT, which might be due to its removal by aerobic biodegradation. Contrarily, the removal efficiency of triclosan showed a negative correlation with HRT (although non-significant) (Figure 2; Table S7, Supplementary Materials), its removal is ascribed to photodegradation and anaerobic biodegradation (Table 4). Nevertheless, Vystavna et al. [12] observed the higher removal efficiency of triclosan with an increase in HRT from 10 to 13 days (50\% and 97\%, respectively) (Table S4, Supplementary Materials). The longer HRT enhances the performance of the system, but a smaller land area expected with a shorter HRT could lower the cost of operation [11]. Herrera-Cárdenas et al. [11] reported the enhanced removal efficiency of galaxolide, tonalide, and methyl dihydrojasmonate in an HFCW at an HRT of five days $(79 \%, 86 \%$, and $70 \%$, respectively) but with a shorter HRT of three days, the removal efficiency was comparatively less (about 50\%), and hence, the toxicity of the effluent was higher.

\subsection{Influence of Physicochemical Parameters of CWs on the Removal of PCPs}

The physicochemical parameters of CWs such as $\mathrm{pH}$, temperature, and effluent DO influence the removal of PCPs, which is evident by the statistics of Pearson correlation among physicochemical parameters and the removal efficiency of PCPs (Figure 2; Table S7, Supplementary Materials).

\subsection{1. $\mathrm{pH}$}

The development of plants as well as nitrification and heterotrophic microbial activities in CWs requires optimal $\mathrm{pH}$ values (near neutral) [2,47]. The $\mathrm{pH}$ of the influent wastewater controls several biotic processes [2] and the degree of ionization of the ionizable compounds [48], therefore, it can be considered an important parameter. The presence of plants in CWs regulates the $\mathrm{pH}(\sim 7.5)$ and influences the treatment performance [49]. The high effluent $\mathrm{pH}$ affects the adsorption behavior of EOCs due to their dissociation and subsequent attachment to soil/sediment by ion exchange [45]. Additionally, the $\mathrm{pH}$ of the system is positively correlated with $\mathrm{DO}$, which enhances the removal of PCPs for which aerobic conditions are more favorable. The $\mathrm{pH}$ value showed a positive correlation with the removal efficiency of two of the six studied PCPs (galaxolide and tonalide) (Figure 2; Table S7, Supplementary Materials), which might be due to the fact that one of their major removal mechanisms is adsorption (Table 4). On the other hand, the negative correlation (although non-significant) of the removal efficiency of triclosan and oxybenzone (Figure 2; Table S7, Supplementary Materials), which are removed by adsorption and/or sorption processes (Table 4), as well as the negative correlation of the removal efficiency of methyl dihydrojasmonate and methylparaben (Figure 2; Table S7, Supplementary Materials), which are removed by plant uptake and aerobic biodegradation (Table 4), designates that other physicochemical parameters might play a more significant role in their removal in CWs.

\subsubsection{Temperature}

Temperature exhibited a positive correlation with the removal efficiency of five of the six studied PCPs, although significant positive correlation with the removal efficiency of galaxolide, methyl dihydrojasmonate, and tonalide (Figure 2; Table S7, Supplementary Materials). Some studies revealed that microbial degradation is their possible removal pathway in CWs, which is enhanced at warm temperature $\left(15-25{ }^{\circ} \mathrm{C}\right)$, particularly in the case of nitrifying and proteolytic bacteria $[2,9,15,47]$. The positive correlation of the removal efficiency of PCPs with temperature verifies that biodegradation is one of the removal pathways in the case of methyl dihydrojasmonate and triclosan (Table 4) and sorption onto organic surfaces in the case of galaxolide and tonalide (Table 4), which are enhanced at warm temperature $[2,3,10,15,21]$. This can be explained by the higher removal efficiency of galaxolide and tonalide at high temperature (in summer) (65 $\pm 24 \%$ and $62 \pm 21 \%$, respectively) compared with low temperature (in winter) ( $42 \pm 26 \%$ and $45 \pm 26 \%$, respectively) (Table S8, Supplementary Materials). 
Contrarily, the better removal efficiency of triclosan at low temperature $(45 \%)$ compared with high temperature (35\%) [15] (Table S4, Supplementary Materials) was ascribed to its adsorption onto soil particles following complex formation with metal ions because the abiotic processes like adsorption are exothermic processes and favored by low temperature [21]. The positive correlation of the removal efficiency of methylparaben with temperature (although non-significant) might be due to its removal by plant uptake and biodegradation (Table 4). Matamoros et al. [15] reported the comparatively better removal efficiency of methylparaben at high temperature than at low temperature (56\% and 33\%, respectively) (Table S4, Supplementary Materials). The major removal mechanisms of oxybenzone are biodegradation and sorption, which are enhanced at higher temperature. However, the removal efficiency of oxybenzone shows a negative correlation with temperature, which is in agreement with the limited available evidence. For instance, Matamoros et al. [15] reported the comparatively better removal efficiency of oxybenzone at low temperature than at high temperature (87\% and $78 \%$, respectively) (Table S4, Supplementary Materials), which suggests that adsorption might contribute to its removal at low temperature.

\subsubsection{Effluent DO}

The effluent DO exhibits a positive correlation with the removal efficiency of five of the six studied PCPs, although a significant positive correlation is with the removal efficiency of galaxolide, tonalide, and triclosan (Figure 2; Table S7, Supplementary Materials), which represents the importance of DO in the removal processes of these PCPs as noted by several studies (e.g., References [3,6,7]). For instance, Ávila et al. [6] attributed the enhanced removal efficiency of tonalide (83\%) in aerated (AA) VFCW compared with non-aerated (NA) VFCW (61\%) to the elevated level of DO in AA-VFCW compared with NA-VFCW (5.2 and $3.4 \mathrm{mg} \mathrm{L}^{-1}$, respectively) (Table S3, Supplementary Materials). Similarly, the authors observed the better removal efficiency of oxybenzone and triclosan in AA-VFCW (91\% and 86\%, respectively) compared with NA-VFCW (89\% and 73\%, respectively). The available evidence suggests that aerobic biodegradation is one of the major removal mechanisms of methyl dihydrojasmonate, triclosan, and oxybenzone in CWs (Table 4). Although some studies attributed the removal of methylparaben to aerobic biodegradation (Table 4), the removal efficiency of this PCP with effluent DO revealed a negative correlation (although non-significant) (Figure 2; Table S7, Supplementary Materials), which is in contradiction with our expectations and difficult to explain based on available studies.

\subsection{Effect of Plants and Support Matrix of CWs on the Removal of PCPs}

In this section, the effect of plants and support matrix of CWs on the removal of PCPs is synthesized based on the available evidence in the studies, which are examined in this review.

\subsubsection{Effect of Plants}

Several studies suggested that biotic pathways such as microbial and plant uptake are the most feasible degradation mechanisms for some PCPs $[1,2,8,10,18,20,32,38]$. The removal efficiency in the planted beds was improved compared with unplanted beds due to stimulatory effects of plants presences such as degradation by enzymatic exudates and insulation against low temperatures [2]. Additionally, plant roots facilitate the release of oxygen and root exudates (such as carbohydrates and amino acids) in the rhizosphere, which provide favorable conditions for the growth of microorganisms and promote aerobic degradation (e.g., References $[2,13,43])$. Several plants like Phragmites australis, Typha angustifolia, and Typha latifolia, which are examined for the treatment of PCPs in CWs, showed their contribution in the removal of PCPs [2,32]. For instance, Petrie et al. [32] observed the uptake of methylparaben by Phragmites australis and calculated its high concentration $\left(197 \mu \mathrm{g} \mathrm{kg}^{-1}\right)$ in the plants. The authors reported the distribution of methylparaben in different parts of the plant. Its concentration within the roots was $152 \mu \mathrm{g} \mathrm{kg}^{-1}$ and within the stem was in the range of 106-246 $\mu \mathrm{g} \mathrm{kg}^{-1}$. However, its higher concentration in the leaves $\left(352 \mu \mathrm{g} \mathrm{kg}^{-1}\right)$ indicated that the rate of its 
translocation within the plant is higher than the rate of transformation. Anjos et al. [31] reported the almost similar removal efficiency of methylparaben in FWSCW planted with Landoltia punctata and Lemna minor ( $91 \%$ and $89 \%$, respectively).

Some studies designated the inconsistent effect of different plant species on the removal of a certain PCP in CWs. For instance, Hijosa-Valsero et al. [20] detected the highest concentration of galaxolide in an FWSCW (Typha angustifolia) compared with an HFCW (Phragmites australis) (858 and $220 \mu \mathrm{g} \mathrm{kg}^{-1}$, respectively). Contrarily, Salcedo et al. [13] reported its highest removal in an HFCW (Phragmites australis) compared with two others planted HFCWs (Typha latifolia and Cyperus papyrus). The corresponding removal efficiency was $82 \pm 14 \%, 57 \pm 23 \%$, and $68 \pm 19 \%$, respectively, which was much higher compared with the removal efficiency in an unplanted system $(37 \pm 12 \%)$. Similarly, Hijosa-Valsero et al. [2] revealed that an FWSCW (Phragmites australis) was more efficient for the removal of methyl dihydrojasmonate (96\%) compared with an FWSCW (Typha angustifolia) (82\%). On the contrary, Salcedo et al. [13] reported its highest removal in an HFCW (Typha latifolia) compared with two others planted HFCWs (Phragmites australis and Cyperus papyrus). The corresponding removal efficiency was $90 \pm 9 \%, 68 \pm 17 \%$, and $77 \pm 20 \%$, respectively. The higher removal efficiency with the system planted with Typha latifolia was attributed to its greater transpiration rate compared with other plants. The removal efficiency with the systems planted with Phragmites australis and Cyperus papyrus was somewhat similar to the removal efficiency with an unplanted system $(71 \pm 19 \%)$.

Consistent with the removal of above-mentioned PCPs, Zhao et al. [39] reported that the effect of plant species exists on the removal of triclosan. Its removal efficiency in three HFCWs planted with Typha angustifolia, Salvinia natans, and Hydrilla verticillata was $91 \%, 87 \%$, and $81 \%$, respectively. The highest removal efficiency in an HFCW planted with Typha angustifolia was attributed to the occurrence of highest quantity of bacteria in this $\mathrm{CW}$, which was possibly because of its capability of oxygen release in its rhizosphere. On the other hand, Liu et al. [36] observed its almost similar removal efficiency in three FWSCWs planted with Cattail (98\%), Hornwort (98\%), and Lemna minor (99\%). Although it was not detected in the leaves of Cattail, its concentration estimated in the leaves of Hornwort and Lemna minor was $5.7 \pm 0.2$ and $7.2 \pm 0.5 \mu \mathrm{g} \mathrm{g}^{-1}$, respectively. Analogous to that, Francini et al. [41] indicated its somewhat similar removal efficiency in two VFCWs planted with Phragmites australis and Salix matsudana (84\% and 83\%, respectively). Furthermore, Wang et al. [37] calculated its translocation factor (zero or below 1.0) from roots to the shoots of the plant, which indicates rhizofiltration as one of the sources of its remediation. Although Li et al. [18] reported that Spirodela polyrhiza contributed to its removal that was evident by its removal in a planted FWSCW (95\%) and an unplanted FWSCW (84\%), Button et al. [23] observed its similar and complete removal $(100 \%)$ in a planted VFCW (Phalaris arundinacea) and an unplanted VFCW.

The effect of plants in CWs has also been examined for the removal of galaxolide, methyl dihydrojasmonate, tonalide, and triclosan by considering their removal efficiency in planted and unplanted CWs (Table 1). Statistical comparison was carried out for the removal efficiency of galaxolide, methyl dihydrojasmonate, and tonalide in planted and unplanted CWs as sufficient data were not available in the case of triclosan (Table S8, Supplementary Materials). Although the removal efficiency of galaxolide, methyl dihydrojasmonate, and tonalide was higher in the planted CWs compared with unplanted CWs (Figure 3), the results of the z-Test for comparison of means for statistical significance or non-significance of observed differences (Table S9, Supplementary Materials) indicated non-significant differences in the removal efficiency of methyl dihydrojasmonate and tonalide. The non-significant differences in the removal efficiency of tonalide are consistent with the results obtained by Ávila et al. [50]. They reported that uptake by the plants is not significant for highly hydrophobic compounds. Reyes-Contreras et al. [21] suggested the efficient contribution of plants when they are young because the aging effect (e.g., clogging or shading) might lead to non-significant differences in the treatment performance of planted and unplanted CWs. For instance, the removal efficiency of galaxolide in a planted HCW and an unplanted HCW was $76 \%$ and $69 \%$, respectively. 
The corresponding removal efficiency of methyl dihydrojasmonate was $89 \%$ and $82 \%$, respectively, and the removal efficiency of tonalide was $67 \%$ and $62 \%$, respectively.

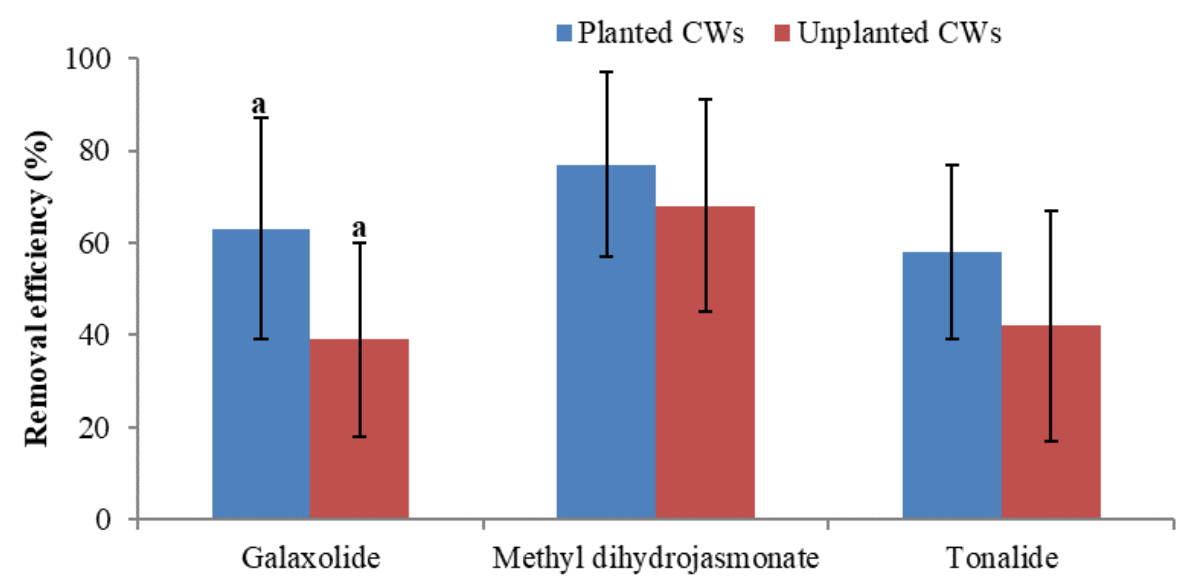

Figure 3. The removal efficiency (mean and standard deviation) of PCPs in planted and unplanted CWs. Note: Galaxolide: "a" shows the significant difference in the removal efficiency in planted and unplanted CWs at $\alpha=0.05$ ( $p<0.05$ ). The number of observations for studied PCPs in planted and unplanted CWs is given in Table S8 (Supplementary Materials).

\subsubsection{Effect of Support Matrix}

Several studies recognized the removal of PCPs in CWs by their adsorption onto substrate media and/or sorption onto organic rich surfaces. Therefore, some recent studies examined the influence of substrate material of high adsorption capacity and surface area on the removal of PCPs. For instance, Xie et al. [24] studied the removal of triclosan as a typical PCP in a VFCW using manganese (Mn) oxides (birnessite) coated sand (B-VFCW) and in a control VFCW without (birnessite) coated sand (C-VFCW). Its removal efficiency was more than $91 \%$ in B-VFCW with the minimum concentration of $5.0 \mathrm{mg} \mathrm{L}^{-1}$. However, in C-VFCW, the average removal efficiency was $84 \%$ with the minimum effluent concentration of $13 \mathrm{mg} \mathrm{L}^{-1}$, which was significantly higher than the B-VFCW $(p<0.05)$. The higher removal in B-VFCW was attributed to the strong adsorptive capacity of Mn oxides and hydrophobicity of triclosan. The amount of triclosan adsorbed by Mn-oxide coated sand was higher $\left(28 \mathrm{ng} \mathrm{g}^{-1}\right)$ compared with the uncoated sand $\left(19 \mathrm{ng} \mathrm{g}^{-1}\right)$. Similarly, Salcedo et al. [13] observed moderate to high removal of galaxolide and methyl dihydrojasmonate in an unplanted HFCW using different substrate material (volcanic gravel and river gravel). The corresponding removal efficiency of galaxolide was $52 \%$ and $50 \%$, respectively, and the removal efficiency of methyl dihydrojasmonate was $86 \%$ and $88 \%$, respectively.

Analogous to that, Ávila et al. [6] verified the efficient performance of an unsaturated sand-based VFCW compared with an unsaturated gravel-based VFCW for the removal of PCPs. The enhanced performance of sand-based VFCW was attributed to a larger available surface area provided by sand media for microbial growth, as well as the provision of higher oxygen to promote the elimination of substances that are mainly removed via aerobic biodegradation process. This is explicit by the higher effluent DO of a sand-based VFCW compared with a gravel-based VFCW (5.5 and $3.4 \mathrm{mg} \mathrm{L}^{-1}$, respectively). The removal efficiency of tonalide, oxybenzone, and triclosan was $61 \%, 89 \%$, and $73 \%$, respectively in the gravel-based VFCW and the corresponding removal efficiency was $78 \%, 96 \%$, and $89 \%$, respectively, in a sand-based VFCW. Consistent with the previous study, the beneficial effect of sand filter was observed for the removal of acesulfame. It was negatively removed in a gravel-based VFCW $(-5 \%)$, but its moderate removal (54\%) was achieved in a subsequent sand-based VFCW [19]. 


\subsection{Effect of Seasonality on the Removal of PCPS}

Several studies reported the effect of seasonality on the removal of PCPs by indicating the difference in their removal efficiency in summer and winter. This might be due to the difference in external temperature, which directly affects water temperature and oxygen solubility $[17,19]$ while regulating the removal processes of PCPs in CWs such as biodegradation, plant uptake, and adsorption/sorption processes. It has been reported that high temperature (in summer) improves biodegradation processes and activity of the plants $[2,3,15,21,47]$ including higher transpiration rate, which is a key variable that determines the rate of PCPs uptake by the plants [3,51] and higher photodegradation rate $[10,52]$. In contrast, the abiotic processes like adsorption being exothermic are favored by low temperature (in winter) [21]. The effluent temperature of the studied CWs in summer and winter was $18 \pm 2$ and $7.0 \pm$ $2.2^{\circ} \mathrm{C}$, respectively, and the corresponding effluent DO was $1.0 \pm 1.4$ and $1.3 \pm 1.6 \mathrm{mg} \mathrm{L}^{-1}$, respectively (Tables S1-S4, Supplementary Materials).

The removal efficiency of 10 PCPs during summer and winter periods is given in Table S8 (Supplementary Materials). Statistical comparison was conducted for the removal efficiency of a few PCPs in summer and winter, as adequate data were not available in other cases (triclosan, tributyl phosphate, triphenyl phosphate, tris (2-chloroethyl) phosphate, cashmeran, methylparaben, and oxybenzone) (Table S8, Supplementary Materials). The results of the z-Test for comparison of means for statistical significance or non-significance of observed differences during summer and winter (Table S9, Supplementary Materials) in the removal efficiency of three PCPs are substantiated by Figure 4 and are discussed in detail.

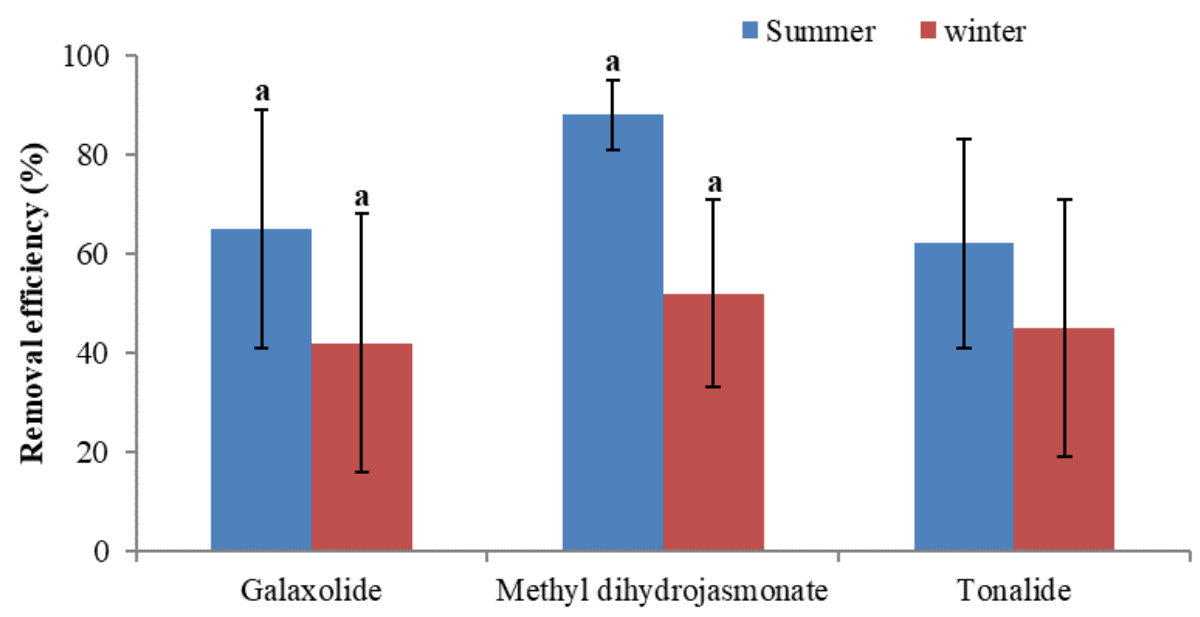

Figure 4. The removal efficiency (mean and standard deviation) of PCPs with different types of CWs in different seasons. Note: Galaxolide and methyl dihydrojasmonate: "a" shows the significant difference in the removal efficiency during summer and winter at $\alpha=0.05(p<0.05)$. The number of observations for studied PCPs for seasonal effect is given in Table S8 (Supplementary Materials).

The removal efficiency of galaxolide was higher in summer $(65 \pm 24 \%)$ compared with winter (42 $\pm 26 \%$ ) (Table S8, Supplementary Materials) and exhibits statistically significant differences (Figure 4; Table S9, Supplementary Materials). This could be due to its sorption onto organic surfaces (Table 4). The roots of the plants in the CWs increase the accumulation of organic matter as well as the sorption capacity [1], which might be enhanced in summer compared with winter due to the higher activity of the rooted plants in the warm season $[2,3,10,15,21]$.

The removal efficiency of methyl dihydrojasmonate was much higher in summer $(88 \pm 7 \%)$ compared with winter ( $52 \pm 19 \%$ ) (Table S8, Supplementary Materials) and shows statistical significance in the differences (Figure 4; Table S9, Supplementary Materials). This could be due to its removal by plant uptake and biodegradation (Table 4 ) that are enhanced in summer $[2,3,15,21]$. 
The removal efficiency of tonalide was comparatively higher in summer (62 $\pm 21 \%)$ than in winter $(45 \pm 26 \%)$ (Table S8, Supplementary Materials) but does not exhibit statistically significant differences (Figure 4; Table S9, Supplementary Materials). Its main removal mechanism is sorption onto organic surfaces (Table 4), which might be enhanced in summer compared with winter. The non-significant seasonal differences in its removal are in agreement with the results of Matamoros et al. [15]. The authors reported its almost similar removal efficiency in an HCW during summer and winter $(88 \%$ and $90 \%$, respectively) (Table S4, Supplementary Materials). Furthermore, the non-significant seasonal differences in the removal efficiency of PCPs could be due to the high presence of root biomass from plants, which could enhance the rhizosphere sorption and plant uptake of PCPs when biodegradation was suppressed in winter [16]. These processes might be the dominant removal pathways of PCPs in winter being less temperature-sensitive compared with biodegradation $[10,16,17,19,21]$. Furthermore, several studies suggested that sorption processes in CWs become more complex when the wastewater matrix becomes more concentrated, possibly due to the competition processes (e.g., References [21,53-55]).

\section{Conclusions}

This paper examines the influence of design and operational factors, and physicochemical parameters of CWs on the removal of PCPs. The research is based on a critical review of the literature and a statistical analysis of available data from peer-reviewed studies. Pearson correlation was done to investigate the effect of design and operational factors (depth, area, HLR, OLR, and HRT), and physicochemical parameters $(\mathrm{pH}$, temperature, and effluent $\mathrm{DO}$ ) of $\mathrm{CWs}$ on the removal efficiency of PCPs. Additionally, the effect of plants and a support matrix of CWs, and the impact of seasonality (summer and winter) on the removal of PCPs were comprehensively and critically evaluated. The specific conclusions obtained from this comprehensive analysis are the following:

1. The design and operational parameters are important governing factors in CWs performance for the removal of PCPs. HLR and HRT showed a significant correlation with the removal efficiency of three out of six studied PCPs, whereas, depth and area were significantly correlated with the removal efficiency of two of the studied PCPs, and OLR was significantly correlated with the removal efficiency of one of the studied PCPs. Nevertheless, the correlation was not significant with the removal efficiency of the same PCPs, which demonstrates that the removal efficiency of PCPs is not affected by only one design and operational parameter but directly or indirectly influenced by all parameters. For instance, the removal efficiency of PCPs showed a significant correlation with three factors such as methylparaben (area, HLR, and OLR) and oxybenzone (depth, HLR, and HRT); two factors such as tonalide (depth and HRT); and one factor such as galaxolide (HRT), methyl dihydrojasmonate (area), and triclosan (HLR).

2. The temperature and effluent DO exhibit a significant correlation with the removal efficiency of most of the studied PCPs (three in both cases), which indicates the importance of DO and temperature for the enhancement of biodegradation, and subsequent removal of PCPs, which are better removed under aerobic conditions. Temperature and effluent DO both showed a significant correlation with the removal efficiency of galaxolide and tonalide. However, the correlation was not significant with the removal efficiency of the same PCPs, which is evident in the case of methyl dihydrojasmonate (temperature) and triclosan (effluent DO). Although $\mathrm{pH}$ did not show a significant correlation with the removal efficiency of any of the studied PCPs, the available evidence indicates that $\mathrm{pH}$ is an important parameter because it controls several biotic processes (e.g., plants development, nitrification, and heterotrophic production) and abiotic processes (e.g., the attachment of ionizable PCPs to soil/sediment via ion exchange).

3. The effect of plants in CWs is explicit by direct uptake of PCPs (methylparaben, propylparaben, and methyl dihydrojasmonate), as well as indirect positive effects such as enhancement in aerobic biodegradation, which was considered as one of the major removal mechanisms of nine out of 15 studied PCPs. The contribution of plants (direct and indirect) in CWs is also evident by the 
higher removal efficiency of PCPs (galaxolide, tonalide, methyl dihydrojasmonate, and triclosan) in planted CWs compared with unplanted CWs.

4. The enhanced performance of CWs can be achieved by using the substrate material of high adsorption capacity, especially for those PCPs (triclosan, cashmeran, galaxolide, tonalide, and oxybenzone), which are mainly removed by adsorption onto the substrate. Furthermore, the substrate material providing a larger surface area for microbial growth and higher oxygen is also suggested to improve the removal efficiency of PCPs, which are mainly removed via aerobic biodegradation pathways (acesulfame, methylparaben, propylparaben, methyl dihydrojasmonate, and sulizobenzone).

5. The comparatively higher removal efficiency of most of the examined PCPs in summer than in winter might be due to the contribution of more removal mechanisms such as biodegradation, plant uptake, and photodegradation at warm temperature. On the contrary, in winter only adsorption/sorption processes are more dominant at low temperature. The removal efficiency of almost all of the studied PCPs demonstrated seasonal differences, but significant difference in the removal efficiency during summer and winter was established in the case of galaxolide and methyl dihydrojasmonate.

Supplementary Materials: The following are available online at http://www.mdpi.com/2073-4441/12/5/1367/s1: Table S1. The performance of FWSCW for personal care products removal; Table S2. The performance of HFCW for personal care products removal; Table S3. The performance of VFCW for personal care products removal; Table S4. The performance of HCW for personal care products removal; Table S5. Physicochemical properties of 15 selected personal care products; Table S6. The removal efficiency (mean \% and standard deviation) of 15 widely studied PCPs in four types of CWs; Table S7. Pearson correlation statistics among the studied factors and six selected PCPs; Table S8. Statistics (mean and standard deviation) of PCPs in planted and unplanted CWs and in different seasons; Table S9. The results ( $p$-values) of $z$-Test for comparison of means for the removal of PCPs in planted and unplanted CWs and in different seasons.

Author Contributions: H.I. developed the concept of the paper, collected data, and conducted review and statistical analysis. She wrote the first draft of the manuscript and subsequently improved it in close consultation with the second author. E.D.v.H. contributed to the improvement of concept and structure of the paper. He reviewed the manuscript and provided comments, which the first author used in revising the manuscript. He also contributed to fine-tuning the writing of the manuscript. All authors have read and agreed to the published version of the manuscript.

Funding: This research received no external funding.

Conflicts of Interest: The authors declare no conflict of interest.

\section{References}

1. Matamoros, V.; Salvadó, V. Evaluation of the seasonal performance of a water reclamation pond-constructed wetland system for removing emerging contaminants. Chemosphere 2012, 86, 111-117. [CrossRef] [PubMed]

2. Hijosa-Valsero, M.; Matamoros, V.; Sidrach-Cardona, R.; Martin-Villacorta, J.; Becares, E.; Bayona, J.M. Comprehensive assessment of the design configuration of constructed wetlands for the removal of pharmaceuticals and personal care products from urban wastewaters. Water Res. 2010, 44, 3669-3678. [CrossRef] [PubMed]

3. Hijosa-Valsero, M.; Matamoros, V.; Pedescoll, A.; Martín-Villacorta, J.; Bécares, E.; García, J.; Bayona, J.M. Evaluation of primary treatment and loading regimes in the removal of pharmaceuticals and personal care products from urban wastewaters by subsurface-flow constructed wetlands. Int. J. Environ. Anal. Chem. 2011, 91, 632-653. [CrossRef]

4. Vymazal, J.; Březinová, T.D.; Koželuh, M.; Kule, L. Occurrence and removal of pharmaceuticals in four full-scale constructed wetlands in the Czech Republic—the first year of monitoring. Ecol. Eng. 2017, 98, 354-364. [CrossRef]

5. Matamoros, V.; Arias, C.; Brix, H.; Bayona, J.M. Removal of pharmaceuticals and personal care products (PPCPs) from urban wastewater in a pilot vertical flow constructed wetland and a sand filter. Environ. Sci. Technol. 2007, 41, 8171-8177. [CrossRef] [PubMed] 
6. Ávila, C.; Nivala, J.; Olsson, L.; Kassa, K.; Headley, T.; Mueller, R.A.; Bayona, J.M.; García, J. Emerging organic contaminants in vertical subsurface flow constructed wetlands: Influence of media size, loading frequency and use of active aeration. Sci. Total Environ. 2014, 494-495, 211-217. [CrossRef]

7. Ávila, C.; Matamoros, V.; Reyes-Contreras, C.; Piña, B.; Casado, M.; Mita, L.; Rivetti, C.; Barata, C.; García, J.; Bayona, J.M. Attenuation of emerging contaminants in a hybrid constructed wetland system under different hydraulic loading rates and their associated toxicological effects in wastewater. Sci. Total Environ. 2014, 470-471, 1272-1280. [CrossRef]

8. Dai, Y.; Tao, R.; Tai, Y.; Tam, N.F.; Dan, A.; Yang, Y. Application of a full-scale newly developed stacked constructed wetland and an assembled bio-filter for reducing phenolic endocrine disrupting chemicals from secondary effluent. Ecol. Eng. 2017, 99, 496-503. [CrossRef]

9. Matamoros, V.; Rodríguez, Y.; Bayona, J.M. Mitigation of emerging contaminants by full-scale horizontal flow constructed wetlands fed with secondary treated wastewater. Ecol. Eng. 2017, 99, 222-227. [CrossRef]

10. Matamoros, V.; García, J.; Bayona, J.M. Organic micropollutant removal in a full-scale surface flow constructed wetland fed with secondary effluent. Water Res. 2008, 42, 653-660. [CrossRef]

11. Herrera-Cardenas, J.; Navarro, A.E.; Torres, E. Effects of porous media, macrophyte type and hydraulic retention time on the removal of organic load and micropollutants in constructed wetlands. J. Environ. Sci. Health Part A 2016, 51, 380-388. [CrossRef] [PubMed]

12. Vystavna, Y.; Frkova, Z.; Marchand, L.; Vergeles, Y.; Stolberg, F. Removal efficiency of pharmaceuticals in a full scale constructed wetland in East Ukraine. Ecol. Eng. 2017, 108, 50-58. [CrossRef]

13. Salcedo, J.J.P.; Montes, G.H.E.; Frómeta, A.E.N.; Osorio, A.C.; Negrete, J.M. Removal of Organic Micropollutants from Riverine Waters using Constructed Wetlands: A Mesocosms Experiment. Int. J. Appl. Eng. Res. 2018, 13, 15740-15748.

14. Ávila, C.; Reyes, C.; Bayona, J.M.; García, J. Emerging organic contaminant removal depending on primary treatment and operational strategy in horizontal subsurface flow constructed wetlands: Influence of redox. Water Res. 2013, 47, 315-325. [CrossRef]

15. Matamoros, V.; Rodríguez, Y.; Albaigés, J.A. comparative assessment of intensive and extensive wastewater treatment technologies for removing emerging contaminants in small communities. Water Res. 2016, 88, 777-785. [CrossRef]

16. Chen, Y.; Vymazal, J.; Březinová, T.; Koželuh, M.; Kule, L.; Huang, J.; Chen, Z. Occurrence, removal and environmental risk assessment of pharmaceuticals and personal care products in rural wastewater treatment wetlands. Sci. Total Environ. 2016, 566-567, 1660-1669. [CrossRef]

17. Kahl, S.; Nivala, J.; Afferden, M.V.; Müller, R.A.; Reemtsma, T. Effect of design and operational conditions on the performance of subsurface flow treatment wetlands: Emerging organic contaminants as indicators. Water Res. 2017, 125, 490-500. [CrossRef]

18. Li, J.; Zhou, Q.; Campos, L.C. Removal of selected emerging PPCP compounds using greater duckweed (Spirodela polyrhiza) based lab-scale free water constructed wetland. Water Res. 2017, 126, 252-261. [CrossRef]

19. Nivala, J.; Kahl, S.; Boog, J.; Afferden, M.; Reemtsma, T.; Müller, R.A. Dynamics of emerging organic contaminant removal in conventional and intensified subsurface flow treatment wetlands. Sci. Total Environ. 2019, 649, 1144-1156. [CrossRef]

20. Hijosa-Valsero, M.; Reyes-Contreras, C.; Domínguez, C.; Bécares, E.; Bayona, J.M. Behaviour of pharmaceuticals and personal care products in constructed wetland compartments: Influent, effluent, pore water, substrate and plant roots. Chemosphere 2016, 145, 508-517. [CrossRef]

21. Reyes-Contreras, C.; Hijosa-Valsero, M.; Sidrach-Cardona, R.; Bayona, J.M.; Bécares, E. Temporal evolution in PPCP removal from urban wastewater by constructed wetlands of different configuration: A medium-term study. Chemosphere 2012, 88, 161-167. [CrossRef] [PubMed]

22. Carranza-Diaz, O.; Schultze-Nobre, L.; Moeder, M.; Nivala, J.; Kuschk, P.; Koeser, H. Removal of selected organic micropollutants in planted and unplanted pilot-scale horizontal flow constructed wetlands under conditions of high organic load. Ecol. Eng. 2014, 71, 234-245. [CrossRef]

23. Button, M.; Cosway, K.; Sui, J.; Weber, K. Impacts and fate of triclosan and sulfamethoxazole in intensified re-circulating vertical flow constructed wetlands. Sci. Total Environ. 2019, 649, 1017-1028. [CrossRef] [PubMed] 
24. Xie, H.; Yang, Y.; Liu, J.; Kang, Y.; Zhang, J.; Hu, Z.; Liang, S. Enhanced triclosan and nutrient removal performance in vertical up-flow constructed wetlands with manganese oxides. Water Res. 2018, 143, 457-466. [CrossRef] [PubMed]

25. Verlicchi, P.; Zambello, E. How efficient are constructed wetlands in removing pharmaceuticals from untreated and treated urban wastewaters? A review. Sci. Total Environ. 2014, 470-471, 1281-1306. [CrossRef]

26. Zhang, D.; Gersberg, R.M.; Ng, W.J.; Tan, S.K. Removal of pharmaceuticals and personal care products in aquatic plant-based systems: A review. Environ. Pollut. 2014, 184, 620-639. [CrossRef]

27. Verlicchi, P.; Zambello, E.; Aukidy, M.A. Removal of Personal Care Products in Constructed Wetlands. In Personal Care Products in the Aquatic Environment; Díaz-Cruz, M.S., Barceló, D., Eds.; The Handbook of Environmental Chemistry; Springer: Cham, Switzerland, 2015; Volume 36, pp. 319-354. [CrossRef]

28. Vo, H.-N.-P.; Bui, X.-T.; Nguyen, T.-M.-H.; Koottatep, T.; Bandyopadhyay, A. Insights of the Removal Mechanisms of Pharmaceutical and Personal Care Products in Constructed Wetlands. Curr. Pollut. Rep. 2018, 4, 93-103. [CrossRef]

29. Gorito, A.M.; Ribeiro, A.R.; Almeida, C.M.R.; Silva, A.M.T. A review on the application of constructed wetlands for the removal of priority substances and contaminants of emerging concern listed in recently launched EU legislation. Environ. Pollut. 2017, 227, 428-443. [CrossRef]

30. Ilyas, H.; van Hullebusch, E.D. Performance comparison of different constructed wetlands designs for the removal of personal care products. Int. J. Environ. Res. Public Health 2020, 17, 3091. [CrossRef]

31. Anjos, M.L.; Isique, W.D.; Albertin, L.L.; Matsumoto, T.; Henares, M.N.P. Parabens Removal from Domestic Sewage by Free-Floating Aquatic Macrophytes. Waste Biomass Valor. 2019, 10, 2221-2226. [CrossRef]

32. Petrie, B.; Rood, S.; Smith, B.D.; Proctor, K.; Youdan, J.; Barden, R.; Kasprzyk-Hordern, B. Biotic phase micropollutant distribution in horizontal sub-surface flow constructed wetlands. Sci. Total Environ. 2018, 630, 648-657. [CrossRef] [PubMed]

33. Chen, J.; Liu, Y.-S.; Deng, W.-J.; Ying, G.-G. Removal of steroid hormones and biocides from rural wastewater by an integrated constructed wetland. Sci. Total Environ. 2019, 660, 358-365. [CrossRef] [PubMed]

34. Sgroi, M.; Pelissari, C.; Roccaro, P.; Sezerino, P.H.; García, J.; Vagliasindi, F.G.A.; Ávila, C. Removal of organic carbon, nitrogen, emerging contaminants and fluorescing organic matter in different constructed wetland configurations. Chem. Eng. J. 2018, 332, 619-627. [CrossRef]

35. Yi, X.; Tran, N.H.; Yin, T.; He, Y.; Gin, K.Y.-H. Removal of selected PPCPs, EDCs, and antibiotic resistance genes in landfill leachate by a full-scale constructed wetlands system. Water Res. 2017, 121, 46-60. [CrossRef] [PubMed]

36. Liu, J.; Wang, J.; Zhao, C.; Hay, A.G.; Xie, H.; Zhan, J. Triclosan removal in wetlands constructed with different aquatic plants. Appl. Microbiol. Biotechnol. 2016, 100, 1459-1467. [CrossRef]

37. Wang, Y.; Yin, T.; Kelly, B.C.; Gin, K.Y.-H. Bioaccumulation behaviour of pharmaceuticals and personal care products in a constructed wetland. Chemosphere 2019, 222, 275-285. [CrossRef]

38. Ávila, C.; Bayona, J.M.; Martín, I.; Salas, J.J.; García, J. Emerging organic contaminant removal in a full-scale hybrid constructed wetland system for wastewater treatment and reuse. Ecol. Eng. 2015, 80, 108-116. [CrossRef]

39. Zhao, C.; Xie, H.; Xu, J.; Xu, X.; Zhang, J.; Hu, Z.; Liu, C.; Liang, S.; Wang, Q.; Wang, J. Bacterial community variation and microbial mechanism of triclosan (TCS) removal by constructed wetlands with different types of plants. Sci. Total Environ. 2015, 505, 633-639. [CrossRef]

40. Park, N.; Vanderford, B.J.; Snyder, S.A.; Sarp, S.; Kim, S.D.; Cho, J. Effective controls of micro-pollutants included in wastewater effluent using constructed wetlands under anoxic condition. Ecol. Eng. 2009, 35, 418-423. [CrossRef]

41. Francini, A.; Mariotti, L.; Gregorio, S.D.; Sebastiani, L.; Andreucci, A. Removal of micro-pollutants from urban wastewater by constructed wetlands with Phragmites australis and Salix matsudana. Environ. Sci. Pollut. Res. 2018, 25, 36474-36484. [CrossRef]

42. Zhu, S.; Chen, H. The fate and risk of selected pharmaceutical and personal care products in wastewater treatment plants and a pilot-scale multistage constructed wetland system. Environ. Sci. Pollut. Res. 2014, 21, 1466-1479. [CrossRef] [PubMed]

43. Hijosa-Valsero, M.; Matamoros, V.; Martin-Villacorta, J.; Becares, E.; Bayona, J.M. Assessment of full-scale natural systems for the removal of PPCPs from wastewater in small communities. Water Res. 2010, 44, 1429-1439. [CrossRef] [PubMed] 
44. Rühmland, S.; Wick, A.; Ternes, T.A.; Barjenbruch, M. Fate of pharmaceuticals in a subsurface flow constructed wetland and two ponds. Ecol. Eng. 2015, 80, 125-139. [CrossRef]

45. Auvinen, H.; Gebhardt, W.; Linnemann, V.; Laing, G.D.; Rousseau, D.P.L. Laboratory- and full-scale studies on the removal of pharmaceuticals in an aerated constructed wetland: Effects of aeration and hydraulic retention time on the removal efficiency and assessment of the aquatic risk. Water Sci. Technol. 2017, 76, 1457-1465. [CrossRef]

46. Dan, A.; Yang, Y.; Dai, Y.-N.; Chen, C.-X.; Wang, S.-Y.; Tao, R. Removal and factors influencing removal of sulfonamides and trimethoprim from domestic sewage in constructed wetlands. Bioresour. Technol. 2013, 146, 363-370. [CrossRef]

47. Truu, M.; Juhanson, J.; Truu, J. Microbial biomass, activity and community composition in constructed wetlands. Sci. Total Environ. 2009, 407, 3958-3971. [CrossRef]

48. Dordio, A.V.; Carvalho, A.J.P. Constructed wetlands with light expanded clay aggregates for agricultural wastewater treatment. Sci. Total Environ. 2013, 463-464, 454-461. [CrossRef]

49. Carvalho, P.N.; Araújo, J.L.; Mucha, A.P.; Basto, M.C.P.; Almeida, C.M.R. Potential of constructed wetlands microcosms for the removal of veterinary pharmaceuticals from livestock wastewater. Bioresour. Technol. 2013, 134, 412-416. [CrossRef]

50. Ávila, C.; Pedescoll, A.; Matamoros, V.; Bayona, J.M.; García, J. Capacity of a horizontal subsurface flow constructed wetland system for the removal of emerging pollutants: An injection experiment. Chemosphere 2010, 81, 1137-1142. [CrossRef]

51. Pilon-Smits, E. Phytoremediation. Ann. Rev. Plant Biol. 2005, 56, 15-39. [CrossRef]

52. Liu, L.; Liu, Y.-H.; Wang, Z.; Liu, C.-X.; Huang, X.; Zhu, G.-F. Behavior of tetracycline and sulfamethazine with corresponding resistance genes from swine wastewater in pilot-scale constructed wetlands. J. Hazard. Mater. 2014, 278, 304-310. [CrossRef] [PubMed]

53. Dordio, A.V.; Teimão, J.; Ramalho, I.; Palace Carvalho, A.J.; Candeias, A.J.E. Selection of a support matrix for the removal of some phenoxyacetic compounds in constructed wetlands systems. Sci. Total Environ. 2007, 380, 237-246. [CrossRef]

54. Dordio, A.V.; Candeias, A.J.E.; Pinto, A.P.; da Costa, C.T.; Carvalho, A.J.P. Preliminary media screening for application in the removal of clofibric acid, carbamazepine and ibuprofen by SSF-constructed wetlands. Ecol. Eng. 2009, 35, 290-302. [CrossRef]

55. Dordio, A.V.; Gonçalves, P.; Texeira, D.; Candeias, A.J.; Castanheiro, J.E.; Pinto, A.P.; Carvalho, A.J.P. Pharmaceuticals sorption behaviour in granulated cork for the selection of a support matrix for a constructed wetlands system. Int. J. Environ. Anal. Chem. 2011, 91, 615-631. [CrossRef] 